\title{
PREDICTION OF CONTAMINANT ACCUMULATION BY FREE-LIVING ORGANISMS: APPLICATIONS OF A SIGMOIDAL MODEL
}

\author{
I. Lehr Brisbin, Jr., ${ }^{*}$ Michael C. Newman, Susan G. McDowell \\ and Eric L. Peters \\ Savannah River Ecology Laboratory, Aiken, South Carolina 29801
}

(Received 24 August 1988; Accepted 29 January 1989)

\begin{abstract}
The accumulation of contaminants by free-living organisms has traditionally been determined with permutations of the deterministic model: $C_{\mathrm{t}}=C_{\mathrm{e}}\left(1-\mathrm{e}^{-k t}\right)$. However, studies utilizing a variety of species and exposure scenarios now suggest that significant deviations may occur from this classic form. In many cases noted to date, these deviations have involved a sigmoidal pattern of accumulation. While there may be no one single causal mechanism responsible for the expression of such a pattern in all cases studied, the application of a flexibly shaped Richards sigmoidal model can improve goodness of fit to the data relative to the classic model form. Several examples are presented for use of the Richards model: accumulation of ${ }^{137} \mathrm{Cs}$ by free-living American coots (Fulica americana) and yellow-bellied turtles (Pseudemys scripta), and $\mathrm{Hg}$ accumulation by mosquitofish (Gambusia affinis).
\end{abstract}

Keywords $-{ }^{203} \mathrm{Hg} \quad \mathrm{Hg} \quad$ Waterfowl Turtle Fish Radioecology

\section{INTRODUCTION}

The accurate prediction of the pattern and rate of contaminant accumulation by free-living organisms is an important aspect of toxicological risk assessment. Traditionally, accumulation is described by the model

$$
\mathrm{d} C / \mathrm{d} t=k_{\mathrm{u}} C_{\mathrm{s}}-k_{\mathrm{d}} C_{\mathrm{t}}
$$

where $\mathrm{d} C / \mathrm{d} t$ is the rate of change of contaminant concentration over time, $C_{\mathrm{s}}$ is the concentration in an infinite source, $C_{\mathrm{t}}$ is the concentration in the organism at time $t, k_{\mathrm{u}}$ is the uptake rate constant and $k_{\mathrm{d}}$ is the depuration or elimination rate constant. At steady state

$$
C_{\mathrm{e}}=k_{\mathrm{u}} C_{\mathrm{s}} / k_{\mathrm{d}},
$$

where $C_{\mathrm{e}}$ is the final contaminant concentration in the organism at steady state or equilibrium. Combining Equations 1 and 2 and assuming that $k_{\mathrm{u}}, k_{\mathrm{d}}$

${ }^{*}$ To whom correspondence may be addressed.

Presented at the Symposium on Toxicokinetics, Eighth Annual Meeting of the Society of Environmental Toxicology and Chemistry, Pensacola, Florida, November $9-12,1987$.

E.L. Peters' current address is Department of Radiology and Radiation Biology, Colorado State University, Fort Collins, CO 80523. and $C_{\mathrm{s}}$ remain constant, the integrated form of the uptake model becomes

$$
C_{\mathrm{t}}=C_{\mathrm{e}}\left(1-\mathrm{e}^{-k_{\mathrm{d}} t}\right),
$$

which indicates that the concentration in the whole body or some organ/tissue compartment increases over time at a rate that is maximal at the time of first exposure. The rate of accumulation then gradually decreases over time until some asymptotic concentration is attained [1-3]. The depuration rate constant relates the rate of contaminant elimination to the concentration of the contaminant in the organism. If the initial concentration in the organism is negligible, $C_{\mathrm{e}}=R / k_{\mathrm{d}}$, where $R$ is the (constant) rate of contaminant intake.

Modifications of this deterministic model may incorporate multiple sources, multiple elimination components, growth, trophic efficiency and internal exchange. However, the enhanced realism associated with such complex models can never be freed from a dependency upon the assumptions associated with the simple model, i.e., constant uptake rate, instantaneous mixing within compartments, time- or age-independent probability of transition between compartments and a negative exponential depuration process for all compartments. Under field conditions, the rate of contaminant intake $(R)$ may not be constant due to 
changes in behavior, food type, food availability or numerous other environmental factors. Significant violations of other assumptions are also likely under field conditions. For example, elimination rate constants for poikilotherms will be linked to seasonal fluctuations in temperature. Also, the probability of elimination of an atom may not be independent of the time that it has resided in the compartment.

We will demonstrate here that, under free-living conditions, the accumulation of contaminants may deviate significantly from the classical pattern and rather may show an S-shaped or sigmoidal pattern of body-burden buildup, characterized by an initial lag in the rate of contaminant uptake as compared to the prediction of Equation 3. Although such deviations from the classic model can be deduced in some cases from a qualitative examination of the data set, a quantitative assessment has not yet been published in which the sigmoidal nature of contaminant accumulation is modeled from empirical data and then shown to deviate statistically from the predictions of Equation 3.

In this report, we will present qualitative assessments of several data sets which suggest initial lags and consequential deviations in contaminant accumulation vs. the commonly used model (Eqn. 3). These will indicate that such deviations can occur for several classes of contaminants and for a variety of organisms and environmental conditions. These conditions will include cases of direct contaminant uptake from water by fish under laboratory conditions, as well as uptake by free-living turtles and waterfowl under conditions where the contaminant is also ingested as the organisms forage in contaminated natural environs.

The wide variety of conditions under which sigmoidal deviations from the classic model can be documented [4-7] make it unlikely that a single causal mechanism can be used to develop a deterministic model that would describe the sigmoidal patterns and initial lags observed. However, such accumulation data can be modeled empirically with a generalized sigmoidal model, similar to that proposed by Richards [8]. When used to model contaminant accumulation, the Richards model can also emulate the classic form of Equation 3 and thereby serve as a basis for determining the degree of statistical significance associated with deviations from the latter.

\section{THE SIGMOIDAL MODEL}

The Richards sigmoidal model was first proposed as a means of analyzing the growth of or- ganisms [8]. Later developments of this model by White and Brisbin [9] and Brisbin et al. [10] have emphasized the use of a process error model and a reparameterization to reduce problems associated with autocorrelation, convergence time and, particularly, rate parameter interpretation. These developments have permitted the use of this model to describe sigmoidal data sets showing a variety of curve shapes while still retaining biologically meaningful interpretations of the defining parameters [11-13].

In the form used to describe contaminant uptake data in the present study, the Richards model is defined by the equation

$$
\begin{aligned}
C_{\mathrm{t}}= & {\left[C_{\mathrm{e}}^{(1-\mathrm{m})}-\left(C_{\mathrm{e}}^{(1-\mathrm{m})}-C_{0}^{(1-\mathrm{m})}\right)\right.} \\
& \left.\times \exp \left(\frac{-2 t}{T}(m+1)\right)\right]^{1 /(1-\mathrm{m})}
\end{aligned}
$$

where $C_{\mathrm{t}}, C_{\mathrm{e}}$ and $t$ are as defined in Equations 1-3, $C_{0}$ is the amount of contaminant in the body or compartment prior to the uptake period, $T$ is the amount of time required for $C_{\mathrm{t}}$ to reach 90 to $95 \%$ of $C_{\mathrm{e}}$ (calculated as the inverse of the proportional weighted mean contaminant uptake rate $[8,10])$ and $m$ is the Richards shape parameter [8]. Varying the numerical value of this shape parameter changes the shape of the model's sigmoidal curve with respect to the time (and ratio of $C_{\mathrm{t}} / C_{\mathrm{e}}$ ) at which the curve attains its point of inflection (i.e., $\mathrm{d} C / \mathrm{d} t$ is maximized). In this sense, the Richards is a general model that can, by varying the value of $m$, generate all of the other commonly used sigmoidal models. When $m=2.0,0.67$ or $\rightarrow 1.0$, the Richards model becomes the logistic, von Bertalanffy or Gompertz model, respectively [8]. Most importantly for the present study, the Richards model becomes the classic model as defined in Equation 3 when $m=0$. In relating Equation 3 to Equation 4 with $m=0$, the parameter $k$ is transformed to $T$, as described by Brisbin et al. [10] (see Eqn. 5). After making such numerical substitutions for $m$ in Equation 4, however, some reparameterization and rearrangement of terms are necessary to produce equations such as the logistic and Gompertz in their classic forms. This would particularly involve retransforming $T$ to an expression defined in terms of $k$ as explained above. The Richards model can be used to test whether a data set fits the classic model by fitting the Richards model and then testing the hypothesis that $m=0$, as will be illustrated below. In these examples, Equation 4 was first fit to accumulation 
data using procedure NLIN of the Statistical Analysis System [14], with $C_{0}$ being directly observed and the parameters $C_{\mathrm{e}}, T$ and $m$ allowed to vary (the "complete" model). This procedure was then repeated with the constraint $m=0$ (the "reduced" model). The consequential increase in residual sums of squares was then evaluated with an $F$ test for the reduced vs. complete models, as described by White and Brisbin [9].

In the case of data for the uptake of ${ }^{203} \mathrm{Hg}$ from water by fish, Equation 4 was modified to produce estimates of $k_{\mathrm{u}}, k_{\mathrm{d}}$ and $m$ under an experimental design that necessitated correction for radiotracer decay during exposure. Initial $\mathrm{Hg}$ concentrations in the fish $\left(C_{0}\right)$ were assumed to be negligible. Equation 4 was then modified by equating $\kappa$, as defined by Richards [8], to $k_{\mathrm{d}}$, as defined in Equation 1. Redefining Richards' [8] definition of $T$ as

$$
T=\frac{2(m+1)(1-m)}{k_{\mathrm{d}}}
$$

and adding a radioactive decay constant $(\lambda)$ for the isotope, Equation 4 was rewritten as

$$
\begin{aligned}
C_{\mathrm{t}}= & {\left[C_{\mathrm{e}}^{(1-\mathrm{m})}\right.} \\
& \left.\times\left(1-\exp \left(\left(-k_{\mathrm{d}} t-\lambda t\right) /(1-m)\right)\right)\right]^{1 /(1-\mathrm{m})} .
\end{aligned}
$$

Although Equation 6 is defined by parameters that are more closely related to previous models of contaminant accumulation, the use of $k_{\mathrm{d}}$ as an equivalent of Richards' $k$ subjects this form of the model to a number of limitations that are avoided when $\kappa$ is transformed to $T$ (Eqn. 4). In particular, when $m$ assumes values very close to 1.0 (the Gompertz model), the value of $\kappa$ becomes unrealistically high and statistical analyses for this parameter across treatment groups may not be meaningful $[10,13]$. Under these conditions, it would be more useful to express Equation 6 in a form in which $\kappa$ is transformed to $T$, which alleviates this problem.

\section{EXAMPLES OF ACCUMULATION ASSESSMENT: RADIOCESIUM IN TURTLES AND WATERFOWL}

Because whole-body burdens of gamma-emitting radionuclides can generally be determined without sacrifice or harm to the subject, such isotopes are ideal for studying the dynamics of contaminant accumulation, particularly in cases where tamed or radiotransmitter-marked subjects can be used to expedite the periodic recapture of specific individuals $[1,2]$. To be meaningful, however, such studies require the use of protected areas of habitat in which uniform contamination of natural food webs has occurred over an extended period of time.

The Pond B reservoir of the U.S. Department of Energy's Savannah River Plant (Aiken, Allendale and Barnwell Counties, SC) received the heated effluents from an operating nuclear production reactor from 1960 to 1964 . These effluents contained about $4.0 \times 10^{15} \mathrm{~Bq}$ of the gamma-emitter ${ }^{137} \mathrm{Cs}$ and various amounts of other radionuclides that were inadvertently leaked to the reactor's effluent system $[15,16]$. The input of reactor effluents to Pond B ceased in 1964 and since that time this reservoir has been undisturbed. More detailed descriptions of Pond B's geochemistry, flora and fauna have been published elsewhere [17-19] along with descriptions of the ecological compartmentalization of the reservoir's present radionuclide inventory [19-20]. As indicated by these studies, ${ }^{137} \mathrm{Cs}$ is the only significant gamma-emitting radionuclide presently incorporated into the reservoir food webs, simplifying detection and quantification of this isotope in the resident biota. Furthermore, the selective concentration of ${ }^{137} \mathrm{Cs}$ in the edible skeletal muscle of fish and game species makes this isotope of particular concern with respect to its potential for introduction into the human diet $[21,22]$.

Recently, two studies have been conducted in the Pond $B$ reservoir which involved release of uncontaminated turtles (Yellow-bellied turtles, Pseudemys scripta) and waterfowl (American coots, Fulica americana), followed by their periodic recapture, whole-body determinations of ${ }^{137} \mathrm{Cs}$ and release of individuals, thus providing data that can be used to demonstrate the sigmoidal nature of the uptake of ${ }^{137} \mathrm{Cs}$ from food and water of the reservoir by these organisms. Preliminary results of the turtle study have been published elsewhere $[23,24]$, but have not yet progressed to the achievement of a steady state of whole-body ${ }^{137} \mathrm{Cs}$ equilibrium. Thus, no attempt has been made to describe these data with a Richards model; rather, data from the first six months of this study are presented here to indicate qualitatively the sigmoidal nature of the accumulation process.

Each of the 10 turtles released into Pond B showed an initial lag in the rate of ${ }^{137} \mathrm{Cs}$ accumulation during the first 20 to $30 \mathrm{~d}$ (Fig. 1), as compared to the prediction of Equation 3, which would require the most rapid rate of isotope accumulation to occur immediately following their release. $\mathrm{Al}$ - 


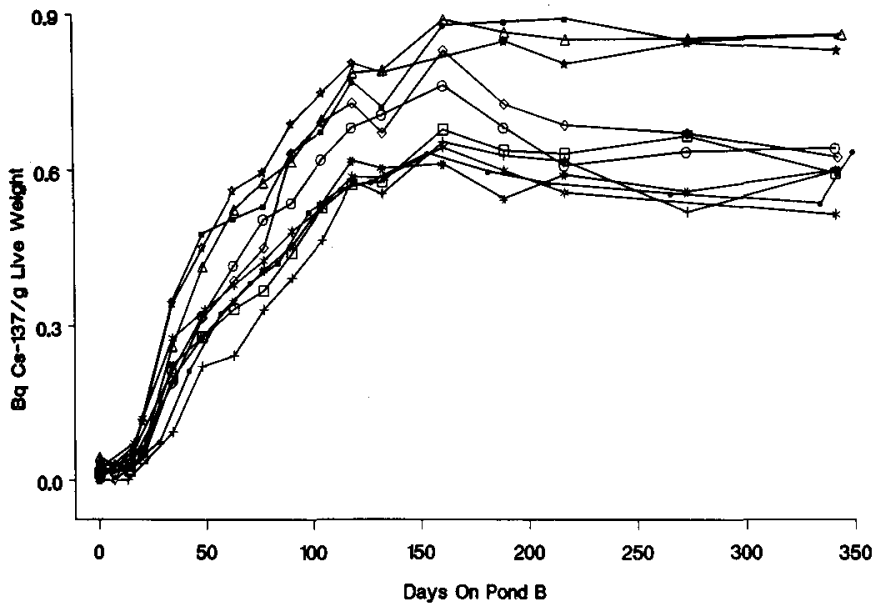

Fig. 1. Accumulation of ${ }^{137} \mathrm{Cs}$ by 10 adult Yellow-bellied turtles following their release in May 1986 on the Pond $B$ reactor cooling reservoir of the U.S. DOE Savannah River Plant. Each curve represents the accumulation history of one individual. Redrawn from Figure 5 of Peters [24] with additional data. Details of counting procedures and experimental errors associated with body burden determination have been provided elsewhere [24]. though data in Figure 1 suggest ${ }^{137} \mathrm{Cs}$ steady-state equilibrium at approximately $150 \mathrm{~d}$, this transient equilibrium state was actually the result of cessation of feeding as the turtles began to decrease their activity and entered a period of winter dormancy (November-February, or 150-250 d following release). With the return of warm weather the following spring, the turtles all resumed normal feeding ${ }_{\mid}$and activity levels; their ${ }^{137} \mathrm{Cs}$ body burdens once again began to increase above those shown at the end of the uptake period covered by Figure 1.

In the waterfowl study, 50 coots were livecaptured in early- to mid-December 1987 from another reactor cooling reservoir about 6 to $7 \mathrm{~km}$ south of Pond $\mathrm{B}$, in which no ${ }^{137} \mathrm{Cs}$ introduction had occurred. These birds were individually subjected to live whole-body gamma counting procedures [25] to verify the absence of significant levels of ${ }^{137} \mathrm{Cs}$, after which they were marked with plastic neck collars, wing-scissored to prevent flight and released on Pond $B$ the day following their capture. Over the next $70 \mathrm{~d}, 13$ live recaptures were made of these birds for subsequent determination of ${ }^{137} \mathrm{Cs}$ whole-body burdens. Although all birds were released again onto Pond B following each ${ }^{137} \mathrm{Cs}$ quantification, no bird was recaptured more than once in the data set used in this study (Fig. 2).

Coots, like most other waterfowl species present on the Savannah River Plant's reservoirs, are almost exclusively winter visitors, with most birds arriving at the site in November to December and

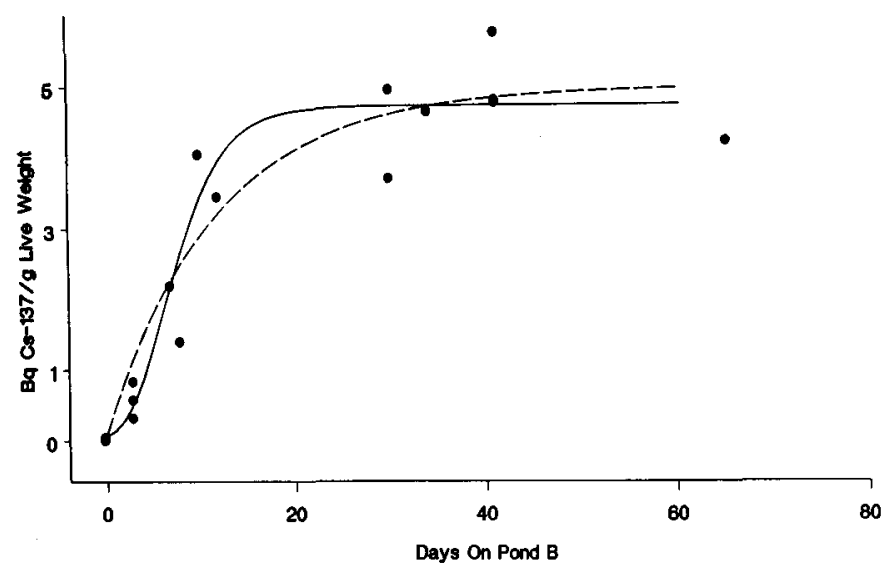

Fig. 2. Accumulation of ${ }^{137} \mathrm{Cs}$ by American coots following their release in December 1987 on the Pond B reactor cooling reservoir of the U.S. DOE Savannah River Plant. Each point represents the recapture of a different individual, except for the point at day $=0$, which represents the average initial body burden of all individuals that were recaptured. Curves represent least-squares fits to the data points, using Equation 4 with either $m$ set $=0$ (dotted curve) or $m$ allowed to vary and converge on a value of $m=1.2$ (solid curve). The goodness of fit of the solid curve was significantly greater than that of the dotted curve ( $p \leqq 0.05$; see text). Details of counting procedures and experimental errors associated with body burden determination have been provided elsewhere [25]. 
departing again for their more northerly breeding grounds in March to April [22,26]. Thus, the birds used in this study were present on the reservoir during the same time as the majority of the waterfowl using this site as their wintering grounds.

As shown by Figure 2, newly released coots, like the turtles described above, also showed an initial lag in their rate of ${ }^{137} \mathrm{Cs}$ accumulation. Since the body burdens of the coots achieved a steadystate equilibrium about $40 \mathrm{~d}$ after release, it was possible to make a quantitative assessment of the degree to which these data differed statistically from the prediction of the classic accumulation model of Equation 3 (as shown by the dotted line of Fig. 2). The classic model tended to overestimate ${ }^{137} \mathrm{Cs}$ levels for the first 5 to $10 \mathrm{~d}$ following release and then underestimated the observed ${ }^{137} \mathrm{Cs}$ levels from 15 to $25 \mathrm{~d}$ after release. However, both models agreed closely with respect to their estimates of asymptotic live-weight body burden (4.98 $\mathrm{Bq} / \mathrm{g}$ vs. $4.73 \mathrm{~Bq} / \mathrm{g}$ for the estimates of $C_{\mathrm{e}}$ from Eqns. 3 and 4, respectively). Application of an $F$ test to the data in Figure 2 indicated that the improvement of fit of Equation 4 over the classic model was statistically significant $(F=5.34 ; d f=$ 1,$11 ; P \leq 0.05$ ). When fit to the accumulation data for the coots, Equation 4 with $m$ set $=0$ produced an estimate of $T=23 \mathrm{~d}$ as the time required to approach $C_{\mathrm{e}}$, as compared to an estimate of $T=14$ $\mathrm{d}$ for the improved fit obtained by allowing the curve shape parameter $(m)$ to vary in the same equation. Under the latter conditions, the best fit estimate of $m$ was 1.2 , with a $95 \%$ asymptotic confidence interval (0.09-2.3) which excludes the value of $m=0$ presumed by Equation 3. The value of $m=1.2$ suggests a curve shape closer to that of the Gompertz sigmoidal model [8], in which the time of most rapid contaminant accumulation would occur at $C_{\mathrm{t}}=(1 / \mathrm{e}) C_{\mathrm{e}}$ or $1.74 \mathrm{~Bq} / \mathrm{g}$ live weight. Substituting $m=1.2, T=14 \mathrm{~d}, C_{0}=0 \mathrm{~Bq} / \mathrm{g}$ and $C_{\mathrm{e}}=4.73 \mathrm{~Bq} / \mathrm{g}$ into Equation 4 and solving for $t$ suggests that this point of inflection would occur approximately $6 \mathrm{~d}$ after the birds began their stay on Pond B.

\section{EXAMPLES OF ACCUMULATION ASSESSMENT: MERCURY IN MOSQUITOFISH}

Using methods similar to those of Newman and Mitz [27], mosquitofish of various sizes were exposed to dissolved mercury (as $\mathrm{HgCl}_{2}$ ) under controlled conditions. Fish were collected from an uncontaminated site on the Savannah River Plant and maintained at $20^{\circ} \mathrm{C}$ with a photoperiod of 14:10 h light:dark. After $10 \mathrm{~d}$ of acclimation, fish were transferred to individual compartments in a 25-liter Plexiglas tank. Plexiglas compartments ranged from $1.5 \times 5 \times 14 \mathrm{~cm}$ to $10.5 \times 26 \times 14 \mathrm{~cm}$ depending on fish size. This arrangement allowed the water within the 25 -liter tank to circulate freely between individual chambers. Fish were exposed to $0.24 \mu \mathrm{g} \mathrm{Hg} / \mathrm{L}$ (as $\mathrm{HgCl}_{2}$ ) and $2.16 \times 10^{6} \mathrm{~Bq} / \mathrm{L}$ of ${ }^{203} \mathrm{HgCl}_{2}$. Gamma activity in each fish was measured at $0,1,2,3,4$ and $6 \mathrm{~d}$ of exposure. The specific activity of the water and the gamma activity in each fish were used to estimate accumulation kinetics of dissolved $\mathrm{Hg}$ (II) by each individual.

Analyses of the $\mathrm{Hg}$ uptake data were undertaken as described previously, with $F$ tests for the complete vs. reduced models again being used, this time using Equation 7 with $m$ either being allowed to vary or being set $=0$, respectively. These analyses (Table 1) indicated that 9 of the 21 fish tested showed $\mathrm{Hg}$ accumulation curves that were better fit when $m$ was allowed to vary (i.e., the hypothesis that $m=0$ was rejected). Twelve of the $21 \mathrm{Hg}$ accumulation curves included 0 in the $95 \%$ asymptotic confidence interval about the estimate of $m$, and 8 of the 9 that did not were those for which the $F$ test also rejected the hypothesis that $m=0$. Estimates of $m$ ranged from -0.786 to 0.916 (Table 1). In all cases except two, negative estimates of $m$ were associated with asymptotic confidence intervals that included $m=0$ and undoubtedly represented artifacts associated with curve-fitting procedures. At the upper extreme, three of the accumulation curves showed estimates of $m$ that exceeded that of the von Bertalanffy sigmoid model (where $m=$ $0.67)$ or, in one case ( $m=0.916)$, even approached that of the Gompertz model (where $m \rightarrow 1.00$ ). There seemed to be a tendency for the smallest fish to show accumulation curves with the highest $m$ values (Table 1).

\section{DISCUSSION}

The conditions under which some of the accumulation data cited in this study were collected might subject them to the claim that experimental artifacts may have been responsible for the sigmoidal nature of the resulting accumulation processes and its observed deviation from the predictions of the classic model. In the case of the turtles, for example, individuals were confined in $115-\mathrm{m}^{2}$ pens in the reservoir to facilitate recapture, and when natural food resources were depleted inside these pens supplementary food resources collected elsewhere in the reservoir had to be provided, as described by Peters [24]. However, these procedures alone should not have produced the sigmoidal deviation observed since natural food resources in 
Table 1. Effects of allowing the Richards model shape parameter $(m)$ to vary freely, as opposed to constraining $m=0$ in Equation 4, on estimates of equilibrium $\left(C_{\mathrm{e}}\right)$ accumulation of inorganic mercury by mosquitofish

\begin{tabular}{|c|c|c|c|c|c|}
\hline \multirow{2}{*}{$\begin{array}{l}\text { Fish } \\
\text { dry wt. } \\
\text { (g) }\end{array}$} & \multirow[b]{2}{*}{$m$} & \multirow[b]{2}{*}{$95 \%$ C.I. for $m$} & \multirow{2}{*}{$\begin{array}{c}F \text { value for } m \\
\text { free to vary } \\
\text { vs. } m=0\end{array}$} & \multicolumn{2}{|c|}{$C_{\mathrm{e}}(\mu \mathrm{g} / \mathrm{g}$ dry wt. $)$} \\
\hline & & & & $\begin{array}{l}m \text { free } \\
\text { to vary }\end{array}$ & $m=0$ \\
\hline 0.391 & -0.506 & $-1.180-0.168$ & 8.773 & 0.539 & 0.501 \\
\hline 0.303 & 0.017 & $-1.162-1.196$ & 0.003 & 0.360 & 0.362 \\
\hline 0.280 & -0.067 & $-0.696-0.562$ & 0.149 & 0.385 & 0.382 \\
\hline 0.275 & -0.128 & $-0.826-0.571$ & 0.393 & 0.347 & 0.334 \\
\hline 0.246 & -0.315 & $-0.601--0.029$ & $17.030^{\mathrm{a}}$ & 0.940 & 0.833 \\
\hline 0.129 & -0.733 & $-1.458--0.007$ & $17.533^{\mathrm{a}}$ & 0.493 & 0.463 \\
\hline 0.122 & 0.822 & $0.670-0.974$ & $89.568^{a}$ & 0.128 & 0.173 \\
\hline 0.095 & -0.598 & $-1.804-0.606$ & 3.588 & 0.813 & 0.756 \\
\hline 0.089 & 0.093 & $-0.661-0.847$ & 0.152 & 0.423 & 0.434 \\
\hline 0.087 & 0.232 & $0.010-0.454$ & 8.345 & 0.210 & 0.218 \\
\hline 0.084 & -0.234 & $-1.391-0.922$ & 0.450 & 0.658 & 0.648 \\
\hline 0.083 & -0.017 & $-0.786-0.751$ & 0.006 & 0.763 & 0.760 \\
\hline 0.081 & -0.160 & $-0.839-0.519$ & 0.619 & 0.445 & 0.436 \\
\hline 0.078 & 0.088 & $-0.278-0.455$ & 0.920 & 0.615 & 0.621 \\
\hline 0.068 & -0.633 & $-1.801-0.535$ & 4.977 & 0.954 & 0.830 \\
\hline 0.041 & -0.480 & $-1.012-0.053$ & $12.876^{\mathrm{a}}$ & 1.034 & 0.967 \\
\hline 0.034 & 0.743 & $0.415-1.072$ & $13.362^{\mathrm{a}}$ & 0.795 & 0.994 \\
\hline 0.024 & 0.422 & $0.206-0.639$ & $21.327^{\mathrm{a}}$ & 0.918 & 0.982 \\
\hline 0.024 & 0.210 & $0.116-0.303$ & $40.671^{\mathrm{a}}$ & 0.956 & 0.997 \\
\hline 0.016 & 0.343 & $0.200-0.486$ & $35.854^{\mathrm{a}}$ & 0.751 & 0.796 \\
\hline 0.007 & 0.916 & $0.748-1.084$ & $30.004^{\mathrm{a}}$ & 1.000 & 1.880 \\
\hline
\end{tabular}

${ }^{\text {a }}$ Hypothesis that $m=0$ is rejected at $p \leq 0.05$.

the pens were maximal at the beginning of the study when accumulation lags with respect to the classic model were most pronounced (Fig. 1). Observed ${ }^{137} \mathrm{Cs}$ accumulation rates later in the experiment when food resources began to wane were actually greater than would have been predicted by the classic model. Moreover, exactly the same initial lags in accumulation and sigmoidal deviations from the classic model were seen in the case of waterfowl (Fig. 2), which were completely free to use the food resources of the entire reservoir. Most of the experimental birds used in this study spent their time foraging with flocks of other free-living coots that, like them but of their own volition, had also recently arrived to begin their winter stay on the Pond B reservoir. Thus, the sigmoidal pattern of ${ }^{137} \mathrm{Cs}$ accumulation shown in Figure 2 must indeed be that of truly free-living migrants, following their arrival for a winter stay at this site.

Since the predictions of the classic model require the assumption of a constant rate of contaminant intake $(R)$ throughout the accumulation period, one explanation for the initial lags in this process shown in Figures 1 and 2 might be an initial reduction in $R$ when an organism such as a turtle or coot is subjected to what must be a certain degree of stress associated with its arrival in a new habitat where it is not yet familiar with either the locations or means of most effectively exploiting the food resources. However, such a "travel lag" hypothesis based in terms of the behavior and ecological regulation of the rate of food (and hence contaminant) intake cannot be used to explain the sigmoidal pattern $(m \neq 0)$ of some of the mosquitofish accumulation curves since no contaminated food was provided and $\mathrm{Hg}$ uptake was directly from the water through physiological processes not subject to alteration by behavioral modification of food intake. Physiological mechanisms that could have potentially contributed to the production of sigmoidal accumulation curves include saturation kinetics for the elimination mechanism [28], time lags before clearance could be facilitated by internal conversion [29], compartmental heterogeneity [30], age dependencies of elemental transitions from compartments [31], homotrophic effects on the uptake mechanism [32] or kinetics of surface mucosal binding $[33,34]$. Time dependence of uptake from one of two sources such as described by Huckabee et al. [35] was not likely since adsorption of mercury onto food and consequent uptake was calculated to be minimal for the fish in this study. 
An important aspect of the analysis of the fish data (Table 1) is the demonstration of the ability of the Richards model to describe contaminant accumulation adequately, whether or not the classic model is the most appropriate. Thus, it is not a question of whether Equation 3 or 4 is "better." Of the two, Equation 4 will always be the more appropriate since it will always give at least some reduction in residual sums of squares (due to the addition of another parameter) and yet it can also become Equation 3 whenever appropriate - as was the case for 12 of the 21 fish reported in Table 1 . The value of the Richards model over its classic counterpart thus lies in its ability also to describe quantitatively, contaminant accumulation in those cases that cannot be adequately described by Equation 3. It should be emphasized, however, that as used above, the term "adequacy," with respect to the superior ability of the Richards vs. classic model to describe uptake data, refers strictly to the ability of the former to show a greater reduction in unexplained statistical variation by making a greater reduction in the residual sums of squares. This does not necessarily imply a superior ability of any one model vs. the other to designate and explain the differences in uptake curve shape that may be observed. However, by providing a statistically objective basis for determining when or if significant deviations from the classic uptake curve shape occur, the Richards model can focus attention upon those particular situations of contaminant uptake that are in need of further study and understanding with respect to the nature of the causality and mechanisms responsible for the deviations observed.

Although the Richards model can adequately describe accumulation data in an empirical sense, it does not provide information concerning the mechanisms responsible for the particular accumulation pattern observed, as would be the case with a more deterministic model. A number of mechanisms may be hypothesized as the basis for such sigmoidal deviations from the classic uptake form, but it is unlikely that any one will adequately explain all of the phenomena under the variety of conditions observed, as discussed above. Nevertheless, efforts to develop deterministic models capable of explaining and emulating observed sigmoidal accumulation patterns under given sets of conditions would still be important and would help in understanding mechanistic phenomena inherent in the sigmoidal accumulation pattern regardless of the circumstances under which it is expressed. For example, in cases where there is a significant initial lag and consequential sigmoidal deviation and yet the equilibrium level of body burden that is eventually attained is still similar to that predicted by the classic model (e.g., Fig. 2, Table 1), there must be a period of accelerated or enhanced contaminant accumulation after the initial lag period, during which contaminant accumulation is actually occurring faster than would be predicted by the classic model. The mechanisms responsible for this phenomenon, which is similar to that of "compensatory" growth [36], may be as important as those mechanisms involved in the initial lag phase in terms of understanding and successfully modeling sigmoidal contaminant accumulation in a deterministic fashion.

Regardless of the mechanisms responsible for sigmoidal patterns of contaminant accumulation, the empirical demonstration and quantification of such phenomena may have great practical importance in toxicological risk assessment and the environmental decision-making processes. In the case of the Chernobyl nuclear accident $[37,38]$, for example, significant contamination with ${ }^{137} \mathrm{Cs}$ and other radionuclides may have occurred over vast areas of wetlands (the so-called "Pripyat Marshes") which have been identified [39] as supporting large numbers of waterfowl during migration as well as the breeding season. Since most migrating waterfowl would only stay in a given area for a short eriod of time, the radionuclide levels in their bodies when they departed would reflect that part of the accumulation period when the predictions of the classic vs. the Richards model would differ to the greatest extent (Fig. 2). After only a 3-d stopover on the Pond B reservoir, for example, migratory coots would depart with ${ }^{137} \mathrm{Cs}$ body burdens that would be over $280 \%$ greater by the prediction of the classic model as compared to the prediction of the improved fit of the Richards sigmoidal model. While in the case of Pond B all of these predicted body burdens, regardless of which model was used, would be well below the level that would represent a health hazard to hunters who might consume them as food, such might not always be the case. In other situations, such as the Chernobyl accident, higher levels of contaminant release might well provide an opportunity for freeliving fish and game species to accumulate body burdens that would cause them to become contaminant vectors to the food chain of man over expanded geographic areas.

Acknowledgement - This work was supported by a contract (DE-AC09-76SROO-819) between the United States 
Department of Energy and the University of Georgia, and a Savannah River Ecology Laboratory Graduate Research Fellowship. Gary C. White provided critical input for the development of the Richards model and stimulating discussions and critical readings of this manuscript were provided by Cham E. Dallas, Phillip M. Dixon, Tom Hinton and F. Ward Whicker. Howard Zippler provided assistance with field studies. Dannette Doubet performed the mercury accumulation experiment. We greatly appreciate the efforts and insights of the anonymous reviewers.

\section{REFERENCES}

1. Whicker, F.W. and V. Schultz. 1982. Radioecology: Nuclear Energy and the Environment, Vols. 1 and 2. CRC Press, Boca Raton, FL.

2. Fendley, T.T., M.N. Manlove and I.L. Brisbin, Jr. 1977. The accumulation and elimination of radiocesium by naturally contaminated wood ducks. Health Phys. 32:415-422.

3. Davis, J.J. and R.F. Foster. 1958. Bioaccumulation of radioisotopes through aquatic food chains. Ecology 39:530-535.

4. Giesy, J.P., J.W. Bowling, H.J. Kania, R.L. Knight and S. Mashburn. 1981. Fates of cadmium introduced into channels microcosm. Environ. Int. 5:159-175.

5. Boudon, A. and F. Ribeyre. 1983. Contamination of aquatic biocenoses by mercury compounds: An experimental ecotoxicological approach. In J.O. Nriagu, ed., Aquatic Toxicology. John Wiley \& Sons, New York, NY, pp. 74-116.

6. Shin, E.B. and P.A. Krenkel. 1976. Mercury uptake by fish and biomethylation mechanisms. $J$. Water Pollut. Control Fed. 48:473-501.

7. McKim, J.M., G.F. Olson, G.W. Holcombe and E.P. Hunt. 1976. Long-term effects of methylmercuric chloride on three generations of brook trout (Salvelinus fontinalis): Toxicity, accumulation, distribution and elimination. J. Fish. Res. Board Can. 33:2726-2739.

8. Richards, F.J. 1959. A flexible growth function for empirical use. J. Exp. Botany 10:290-300.

9. White, G.C. and I.L. Brisbin, Jr. 1980. Estimation and comparison of parameters in stochastic growth models for barn owls. Growth 44:97-111.

10. Brisbin, I.L., Jr., G.C. White and P.B. Bush. 1986. PCB intake and the growth of waterfowl: Multivariate analyses based on a reparameterized Richards sigmoid model. Growth 50:1-11.

11. Brisbin, I.L., Jr., G.C. White, P.B. Bush and L.A. Mayack. 1986. Sigmoid growth analyses of wood ducks: The effects of sex, dietary protein and cadmium on parameters of the Richards model. Growth 50:41-50.

12. Brisbin, I.L., Jr., K.W. McLeod and G.C. White. 1986. Sigmoid growth and the assessment of hormesis: A case for caution. Health Phys. 52:553-559.

13. Brisbin, I.L., Jr., C.T. Collins, G.C. White and D.A. McCallum. 1987. A new paradigm for the analysis and interpretation of growth data: The shape of things to come. The $A u k$ 104:552-554.

14. SAS Institute, Inc. 1982. $S A S^{\circledast}$ User's Guide. Cary, NC.

15. Ashley, C. and C.C. Ziegler. 1980. Releases of radioactivity at Savannah River Plant 1954 through 1978.
Report DPSU-75-25-1. E.I. DuPont de Nemours and Co., Aiken, SC.

16. Alberts, J.A., J.W. Bowling, J.E. Schindler and D.E. Kyle. 1990. Seasonal dynamics of physical and chemical properties of a warm monomictic reservoir. Verh. Intern. Verein. Limnol. (in press).

17. Ruhe, R.V. and E.A. Matney. 1980. Clay mineralogy of selected sediments and soils. Savannah River Laboratory, E.I. DuPont de Nemours and Co., Aiken, $\mathrm{SC}$.

18. Parker, E.D., M.F. Hirshfield and J.W. Gibbons. 1973. Ecological comparisons of thermally affected aquatic environments. J. Water Pollut. Control Fed. 45:726-733.

19. Whicker, F.W., J.W. Bowling, M.S. Kelly, J.E. Pinder III, K.A. Orlandini and J.J. Alberts. 1986. Inventories of ${ }^{137} \mathrm{Cs}$, ${ }^{90} \mathrm{Sr}$, and ${ }^{239,240} \mathrm{Pu}$ in Pond $\mathrm{B}$ : Implications for the relative importances of radionuclide cycling processes in lake ecosystems. 1986 Annual Report. Savannah River Ecology Laboratory, Aiken, SC, pp. 17-23.

20. Brisbin, I.L., Jr. 1989. Radiocesium levels in a population of American alligators: A model for the study of environmental contaminants in free-living crocodilians. In F.W. King, ed., Proceedings, Eighth Working Meeting of the IUCN/SSC Crocodile Specialist Group. International Union for the Conservation of Nature and Natural Resources, Gland, Switzerland, pp. 60-73.

21. Jenkins, J.H. and T.T. Fendley. 1968. The extent of contamination, detection and health significance of high accumulations of radioactivity in southeastern game populations. Proc. 22nd Annu. Conf. S.E. Game Fish Comm. 22:89-95.

22. Brisbin, I.L., Jr., R.A. Geiger and M.H. Smith. 1973. Accumulation and redistribution of radiocesium by migratory waterfowl inhabiting a reactor cooling reservoir. Proceedings, International Symposium on the Environmental Behavior of Radionuclides Released in the Nuclear Industry. International Atomic Energy Agency, Vienna, Austria, pp. 373384.

23. Peters, E.L. and I.L. Brisbin, Jr. 1988. Radiocesium elimination in the yellow-bellied turtle (Pseudemys scripta). J. Appl. Ecol. 25:461-471.

24. Peters, E.L. 1986. Radiocesium kinetics in the yellow-bellied turtle (Pseudemys scripta). M.Sc. thesis, University of Georgia, Athens, GA.

25. Potter, C. 1987. Use of reactor cooling reservoirs and cesium-137 uptake in the American coot (Fulica americana). M.Sc. thesis, Colorado State University, Fort Collins, $\mathrm{CO}$.

26. Brisbin, I.L., Jr. 1974. Abundance and diversity of waterfowl inhabiting heated and unheated portions of a reactor cooling reservoir. In J.W. Gibbons and R.R. Sharitz, eds., Thermal Ecology. AEC Symposium Series CONF-730505. National Technical Information Service, Springfield, VA, pp. 579-594.

27. Newman, M.C and S.V. Mitz 1988. Size dependence of zinc elimination and uptake from water by mosquitofish, Gambusia affinis (Baird and Girard). Aquat. Toxicol. 12:17-32.

28. Spacie, A. and J.L. Hamelink. 1985. Bioaccumulation. In G.M. Rand and S.R. Petrocelli, eds., Fundamentals of Aquatic Toxicology. Hemisphere Publishing Corp., New York, NY, pp. 495-525. 
29. Matis, J.H. 1972. Gamma time-dependency in Blaxter's compartmental model. Biometrics 28:597-602.

30. Matis, J.H., T.E. Wehrly and K.B. Gerald. 1983. The statistical analysis of pharmacokinetic data. In S. Levin, ed., Lecture Notes in Biomathematics: Tracer Kinetics and Physiologic Modeling. SpringerVerlag, New York, NY, pp. 1-59.

31. Hughes, T.H. and J.H. Matis. 1984. An irreversible two-compartment model with age-dependent turnover rates. Biometrics 40:501-505.

32. Piszkiewicz, D. 1977. Kinetics of Chemical and Enzyme-Catalyzed Reactions. Oxford University Press, New York, NY.

33. Farmanfarmaian, A. 1985. Fractional distributions of ${ }^{203} \mathrm{HgCl}_{2}$ and $\mathrm{CH}_{3}{ }^{203} \mathrm{HgCl}$ in the intestine of a marine fish. Marine Environ. Res. 17:176-180.

34. Part, P.R. and A.C. Lock. 1983. Diffusion of calcium, cadmium and mercury in a mucous solution from rainbow trout. Comp. Biochem. Physiol. 76C:259-263.
35. Huckabee, J.W., R.A. Goldstein, S.A. Janzen and S.E. Woock. 1975. Methylmercury in a freshwater food chain. Symposium Proceedings: International Conference on Heavy Metals in the Environment, Vol. II, Part 1. National Research Council of Canada, Toronto, Ontario, Canada, pp. 191-215.

36. Goss, R.J. 1965. Kinetics of compensatory growth. Q. Rev. Biol. 40:123-146.

37. Hohenemser, C., M. Deicher, A. Ernst, H. Hofsass, G. Lindner and E. Recknagel. 1986. Chernobyl: An early report. Environment 28:6-13, 30-43.

38. Medvedev, Z.A. 1986. Ecological aspects of the Chernobyl nuclear plant disaster. Trends Ecol. Evol. 1:23-25.

39. Isakov, Y.A. 1966. MAR Project and conservation of waterfowl breeding in the USSR. Proceedings, Second European Meeting on Wildfowl Conservation. International Waterfowl Research Bureau, Slimbridge, U.K., pp. 125-138. 